\title{
Epidemiology of Hepatitis B Virus Infection in China: Current Status and Challenges
}

\author{
Yong-Ping Yan, Hai-Xia Su, Zhao-Hua Ji, Zhong-Jun Shao and Zhong-Shu Pu \\ Department of Epidemiology, and the Ministry of Education Key Lab of Hazard Assessment and Control in Special Operational \\ Environment, Fourth Military Medical University, Xi'an, Shaanxi, China
}

\begin{abstract}
The prevalence of hepatitis $B$ is high in China. Based on the National Disease Supervision Information Management System of China, the mean reported incidence of hepatitis $B$ was 84.3 per 100,000 in China between 2005 and 2010. There are differences in population distribution based on region and ethnic group. Here, risk factors, virological characteristics, and prophylaxis of hepatitis B in China are reviewed. Although the prevalence of HBV infection is gradually declining, there are many challenges in HBV infection control, including higher prevalence in floating population, poor compliance of antiviral therapy, and high disease burden.

(C) 2014 The Second Affiliated Hospital of Chongqing Medical University. Published by XIA \& HE Publishing Ltd. All rights reserved.
\end{abstract}

\section{Introduction}

Worldwide, China has been identified as an area with a high prevalence of hepatitis B virus (HBV) infection. According to a national cross-sectional seroepidemiological survey in 1992, 120 million people in China were afflicted with HBV infection, with an infection rate of approximately $60 \%$ and prevalence of HBV surface antigen (HBsAg) carriers estimated at $9.8 \%{ }^{1}$ The nationwide survey in 2006 showed that the prevalence of $\mathrm{HBsAg}$ carrier was reduced to less than $8.0 \%$ and the $\mathrm{HBsAg}$ prevalence among children aged $<5$ years was only $1.0 \%{ }^{2}$ Based on the prevalence of HBsAg and HBV infection obtained from the two national seroepidemiological surveys, the numbers of HBV-infected patients and HBsAg carriers have decreased by an estimated 80 million and 20 million, respectively, since 1992 to $2006 .^{3}$ The most serious concern of HBV infection is the risk associated with chronic carriers,

Keywords: Hepatitis B; Epidemiology; Distribution; Prophylaxis; Challenges. Abbreviations: CDC, Center for Disease Control and Prevention; EPI, Expanded Program on Immunization; GWAS, genome wide association study; $\mathrm{HBsAg}, \mathrm{HBV}$ surface antigen, ; HBeAg, HBV e antigen; HBV, hepatitis B virus; HIB, hepatitis B immune globulin; HLA-C, human leukocyte antigen C; NAT, nucleic acid testing; NDSIMS, National Disease Supervision Information Management System; OBI, occult HBV infection; PBMC, mother's peripheral blood mononuclear cells; PCR, polymerase chain reaction; RCT, randomized controlled trial; STD, sexually transmitted disease; UBE2L3, ubiquitin-conjugating enzyme E2 L3.

Received: 23 December 2013; Revised: 7 February 2014; Accepted: 10 February 2014

DOI of original article: 10.14218/JCTH.2013.00030.

Correspondence to: Yong-Ping Yan, Department of Epidemiology, School of Public Health, The Fourth Military Medical University, No. 169, Changle West Road, Xi'an 710032, China. Tel: +86-29-84774868, Fax: +86-29-84774868, E-mail: yanyping@fmmu.edu.cn including chronic hepatitis, hepatic cirrhosis, and even hepatocellular carcinoma. Chronic hepatitis B is associated with approximately $90 \%$ and $30 \%$ of neonatal and childhood HBV infection, respectively, while less than $10 \%$ of adults infected develop chronic hepatitis B. ${ }^{4}$ In China, hepatitis B is a major disease that affects human health, often leading to chronic poverty because of it high prevalence, persistence, and difficult treatment. Therefore, controlling HBV infection has become a top priority for the Chinese government. This review describes the epidemiology and prophylaxis of $\mathrm{HBV}$ infection, as well as the challenges of hepatitis B control in China.

The characteristics of notified incidence of hepatitis B in China

Since 2004, patients with hepatitis B identified at the institutions involved in disease control and prevention, blood collection, and supply in China are directly reported within 24 hours to the different health departments via the National Disease Supervision Information Management System (NDSIMS). The notified incidence of hepatitis B is estimated based on these reported cases.

\section{Time and regional distribution}

For many years, the number of hepatitis B cases reported to NDSIMS has ranked first among all legally notifiable infectious diseases, accounting for approximately a third of the total cases. The reported incidence of hepatitis $B$ gradually increased threefold from 21.5 per 100,000 to 89.0 per 100,000 in 2007 , followed by a slow decline to 79.5 per 100,000 in $2010 .^{5}$ The mean reported incidence of hepatitis $B$ was 84.3 per 100,000 in China during the period 2005 to $2010 .^{6-11}$

In 31 provinces in China, the reported incidences of hepatitis B varied greatly. The lowest mean reported incidence from 2005 to 2010 was in Tibet Autonomous Region (14.6 per 100,000$)$, followed by Jiangsu Province ( 21.3 per $100,000)$. The highest was reported in Qinghai Province (283.0 per 100,000$)$, followed by Gansu Province (225.7 per 100,000 persons). The geographical distribution of mean reported incidence of hepatitis B in 31 provinces of China between 2005 and 2010 is shown in Fig. 1.

\section{Population distribution}

Among the reported cases of hepatitis B in China from 2005 to 2007 , the incidence rate was lowest in children aged $<15$ 


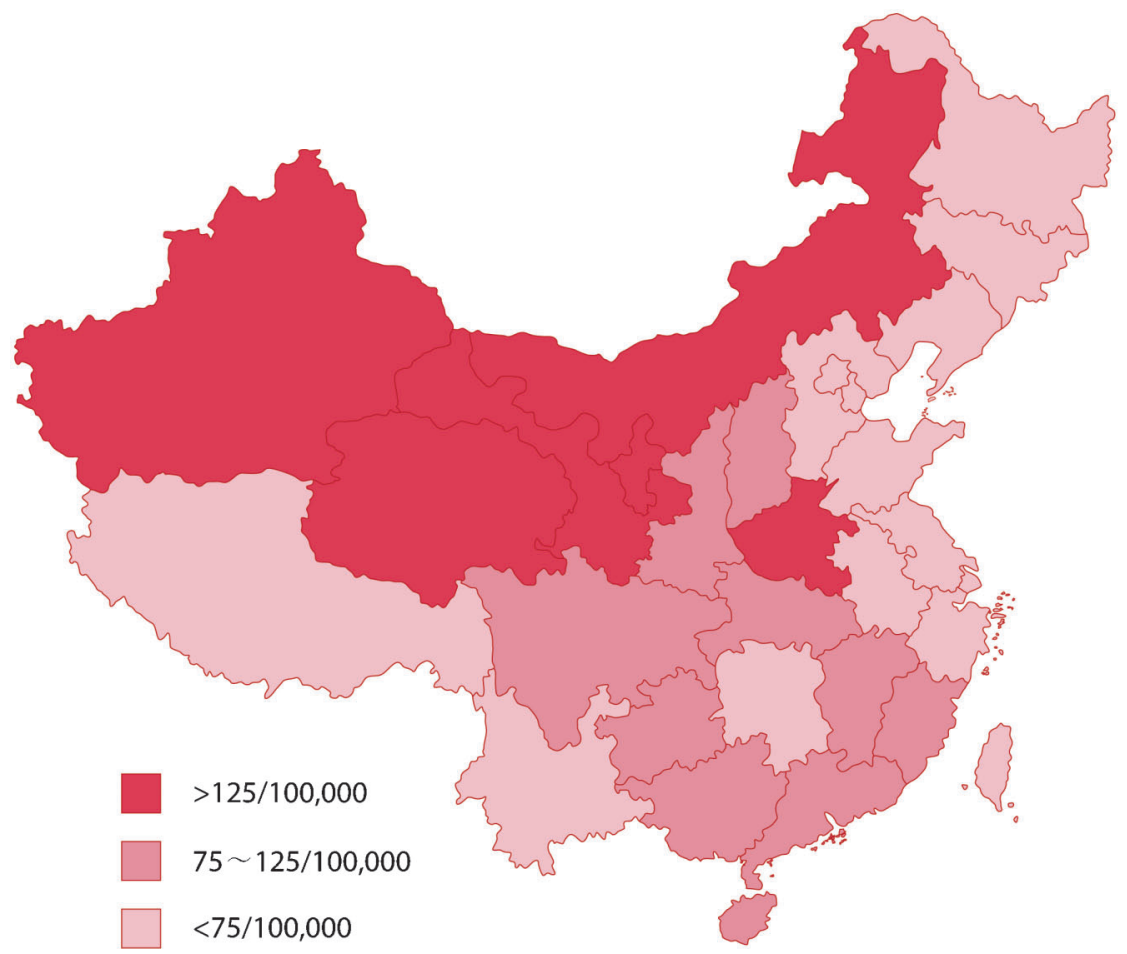

Fig. 1. The distribution of mean reported incidence of hepatitis B in 31 provinces of China between 2005 and 2010.

years. The incidence rate of acute hepatitis $B$ was high among adults aged $\geqslant 15$ years, with the highest incidence rate observed in the population aged 20-29 years. A higher incidence rate of hepatitis $B$ was found in men than women at each age group. ${ }^{12}$ The male to female ratio of the reported cases of acute hepatitis B was 2.21:1, with most patients aged between 15 and 45 years. ${ }^{13}$ Acute hepatitis B was detected in each occupation, with the top 3 being farmers $(44.3 \%)$, students $(12.4 \%)$, and workers $(11.1 \%)$.

\section{Role and issues of the national notified data}

The reported data has been an important evidence-based reference tool to evaluate the risk of hepatitis $B$ for many years and in shaping health policy, such as free neonatal HBV vaccination in China. In addition, hepatitis $B$ was listed as one of the high-priority diseases in the National Key Projects on Prevention and Control of Infectious Diseases initiated in 2008. However, some issues still persist in China's networkbased infectious disease reporting system. For example, the problem of repeated case reports detected between 2004 and 2008 still remains unresolved, with the repeated report rate up to $29.0 \%$ in some areas. ${ }^{14,15}$ In addition, implementation of reporting standards is inconsistent. For example, many HBsAg carriers were reported as acute cases, and the real reported incidence rate of hepatitis $B$ was only about onethird of the reported incidence according to a study from Chinese Center for Disease Control and Prevention (China $\mathrm{CDC}) .{ }^{16}$ Therefore, the need for strong training of grass-roots infectious disease physicians and unified standards for acute hepatitis B case reporting to improve the functioning of China's network-based infectious disease reporting system cannot be overstated. ${ }^{12}$
Risk factors and transmission routes of HBV infection in China

HBV is mainly transmitted through the blood, with mother-toinfant, blood-borne, and sexual transmission constituting the major routes.

\section{Mother-to-infant transmission and risk factors}

Prior to the wide availability of HBV vaccination, it was found that mother-to-infant transmission occurred in $10 \%-30 \%$ infants from $\mathrm{HBsAg}$-positive mothers, while $70 \%-90 \%$ of the infants born to HBsAg and $\mathrm{HBeAg}$ double positive mothers developed chronic HBV infections. ${ }^{17,18}$ Prior to 2002, the mother-to-infant HBV transmission was approximately $16 \%-$ $45 \% .{ }^{19,20}$ The rate of transmission has since been significantly reduced to approximately $3 \%-5 \%$ with the initiation of comprehensive HBV vaccination. However, it was still prevalent up to $7.3 \%$ in some areas. The risk factors include $\mathrm{HBsAg} / \mathrm{HBeAg}$ double positive mothers, untimely HBV vaccination, high HBV DNA viral load, sexual behavior during pregnancy, and untimely HBV vaccination of low-birth-weight and premature infants. ${ }^{21,22}$ Furthermore, amniocentesis performed on $\mathrm{HBsAg}+$ mothers may also increase the risk for vertical transmission. A significantly higher vertical transmission rate was observed in the amniocentesis group vs. the control group ( $50.0 \%$ vs. $4.5 \%$ ), if the maternal HBV DNA levels were $>7 \log _{10}$ copies $/ \mathrm{ml}^{23}$

\section{Blood-borne transmission and risk factors}

Historically, unsafe blood transfusion or use of polluted blood products accounted for most of the HBV transmission in 
China. ${ }^{24}$ In the 1960 s, the incidence of hepatitis reached $50 \%$ after blood transfusion. Serological screening of blood donors for hepatitis virus was done until the late 1970 s, with routine testing for HBsAg since the early 1980s. Since then, HBV transmission through unsafe blood transfusion has been effectively controlled. Stringent HBsAg screening of blood donors since the Blood Donation Law of the People's Republic of China in 1999 led to fewer HBV infections caused by blood transmission or transfusion of blood products. ${ }^{25}$ An investigation of risk factors of acute hepatitis B among eight provinces in China conducted by China CDC showed that populations with a history of paid blood donation and blood transfusion constituted approximately $3 \%$ and $1 \%$ of HBVinfected populations, ${ }^{16}$ respectively, suggesting that blood transmission is no longer the major transmission route. However, blood-borne transmission of HBV still remains. A population-based case-control study in Shanghai showed that invasive medical procedures, sharing shavers and towels with HBV carriers, body care and beauty treatments were independent risk factors for acute hepatitis B. ${ }^{26}$ In addition, pedicures in bathing centers, tattooing and ear piercing may also transmit HBV. ${ }^{27}$

It is estimated that risk of HBV infection by blood transfusion is one in 18,000 in Shenzhen, China, ${ }^{28}$ which is higher than Europe, North America and Australia (ranging from $1 / 70000$ to $1 / 130000) .^{29-31}$ In specific populations, such as hemodialysis patients (20 hemodialysis units of Beijing), the prevalence of HBsAg was only $7.0 \%$, which showed that infection control measures are effective. ${ }^{32}$ Nucleic acid testing (NAT) can be used to identify occult HBV infection and HBV infection during treatment window. However, such testing was not involved in the routine detection based on the Blood Donation Law of the People's Republic of China and the associated administrative regulations. Currently, NAT is only employed for the screening of blood donors in a few large cities and blood stations.

\section{Sexual transmission and risk factors}

Sexual contact with HBV-infected individuals is considered another major route of HBV infection. ${ }^{33}$ In North America and Western Europe where the HBsAg prevalence is lower than $1 \%$, HBV infection spreads through unprotected sexual behaviors and intravenous drug use. Unprotected sexual contact with HBV- infected individuals, especially with multiple sexual partners, increases the risk of HBV infection. Sexual contact is a major risk factor of HBV infection in America, ${ }^{34}$ Taiwan, ${ }^{13}$ Canada, ${ }^{35}$ and UK, ${ }^{36}$ including having multiple sexual partners, male homosexuality, having sex with HBV carriers, and heterosexual contact.

Prior to reforms and opening up of China, HBV transmission through sexual contact was confined to husband and wife. ${ }^{37}$ However, changing attitudes toward sex led to resurgence of sexually transmitted diseases (STD) such as syphilis, with rising prevalence of HBV infection through sexual contact transmission. Results from the 2006 national seroepidemiological survey of HBV infection showed that the HBsAg prevalence was $10.5 \%$ in populations aged $20-30$ years and $5.4 \%$ in populations aged $15-19$ years, suggesting significance of transmission of HBV through sexual contact in a sexually active population. ${ }^{2}$ In addition, a study to investigate the prevalence of hepatitis $B$ in Shandong Province from 1990 to 2007 showed that $35.7 \%$ of the reported cases were aged from 15 to 29 years, ${ }^{38}$ and the prevalence of HBV infection increased from $7.5 \%$ in 2004 to $10.3 \%$ in 2006 among homosexuals. ${ }^{39}$ These results suggested that efforts to vaccinate adults against HBV should be strengthened in addition to routine immunization and vaccination supplementation among children aged less than 15 years, to effectively control the sexual transmission of HBV in adults.

Additionally, host susceptibility is an important risk factor for outcome of HBV infection. Recently, a three-phase genome wide association study (GWAS) ${ }^{40}$ on HBV carriers and controls from the general population highlight the importance of human leukocyte antigen (HLA)-C and ubiquitin conjugating enzyme E2 L3 (UBE2L3) in the clearance of HBV infection in addition to HLA-DP and HLA-DQ.

\section{Virological characteristcs of HBV infection in China}

\section{HBV genotype and subgenotype}

Nine HBV genotypes (A-I) have been identified based on $8 \%$ or more differences in viral whole-genome sequence. ${ }^{41}$ In China, five genotypes A-E were detected. ${ }^{42,43}$ Genotypes C and $B$ were the predominant strains in patients with chronic HBV infection, which accounted for about $60 \%$ and $12 \%, 42,43$ respectively. Genotype $B$ was more frequently detected in acute HBV infection compared with chronic hepatitis $B$ and acute-on-chronic liver failure. ${ }^{44}$ HBV genotypes have a distinct geographical distribution. ${ }^{42}$ Genotype C was dominant in the northern region of China; genotypes $B$ and $C$ were common in the south; genotype D was often found among ethnic minorities in Tibet, Xinjiang, and Gansu provinces; genotype A was rare; and genotype $E$ was only found among Dai Nationality in Yunnan Province. ${ }^{45}$ The genotype data from nine provinces showed that genotype $C$ was predominant in the eastern (Shandong and Jiangsu), southern (Guangdong and Guangxi), northern ( Jilin and Beijing ), and central regions (Henan and Hebei) (Table 1$).{ }^{42}$ In the western region (Tibet, ${ }^{46}$ Xinjiang, ${ }^{42}$ and Qinghai ${ }^{47}$ ), genotype D was more common, especially in Tibetans and Uighurs.

HBV was also classified into different subgenotypes, according to genome sequence divergence from $4.0 \%$ to $8.0 \%$. Genotype B was divided into B1-B7, genotype C and D also were divided into 6 and 7 subgenotypes, respectively. ${ }^{42}$ Subgenotypes B1, B2 and C1, C2 and D1 were detected in China. ${ }^{42,44,48}$ B2 $(90.8 \%)$ and C2 $(94.0 \%)$ were the main subgenotype of genotype $B$ and C. ${ }^{42,44}$

Serosubtypes were determined based on HBsAg amino acids $122,127,160$, and 159. ${ }^{49,50}$ Serosubtypes adr, adw2, ayr, ayw1, ayw2, and ayw3 were detected based on HBV sequences in 280 chronic carriers in four provinces ${ }^{49}$ (Hunan, Guangxi, Henan and Hebei). The adr and adw2 were predominant serosubtypes, accounting for $64.3 \%$ and $31.4 \%$, respectively. ${ }^{49}$

\section{Mixed genotype infection}

Mixed genotype infections were common in each of the regions. Mixed genotypes $\mathrm{B}$ and $\mathrm{C}$ were most frequently detected, followed by genotypes $C$ and D. ${ }^{42,43}$ Mixed genotypes $B$ and $D, A$ and $C$, or $B, C$, and $D$ were rare. ${ }^{42,51,52}$

In the southern region, including Tibet and Xinjiang provinces, the proportion of mixed infection of genotype $C$ and $D$ was higher, and recombinations of $C$ and $D, B$ and $C$ 
Yan YP et al: Epidemiology of HBV infection in China

Table 1. HBV genotype distribution in China ${ }^{[42]}$

\begin{tabular}{llllllllll}
\hline & & \multicolumn{2}{l}{ Genotype B } & \multicolumn{2}{l}{ Genotype C } & \multicolumn{2}{l}{ Genotype D } & \multicolumn{2}{c}{ Mixed Genotypes } \\
\cline { 3 - 9 } Region & Cases & Cases & Percentage (\%) & Cases & Percentage (\%) & Cases & Percentage (\%) & Cases & Percentage (\%) \\
\hline eastern & 148 & 28 & 18.9 & 106 & 71.6 & 3 & 2.0 & 11 & 7.4 \\
western & 116 & 13 & 11.2 & 31 & 26.7 & 37 & 31.9 & 35 & 30.2 \\
southern & 110 & 24 & 21.8 & 61 & 55.5 & 3 & 2.7 & 22 & 20.0 \\
northern & 199 & 4 & 2.0 & 182 & 91.5 & 1 & 0.5 & 12 & 6.0 \\
central & 162 & 7 & 4.3 & 148 & 91.4 & 2 & 1.2 & 5 & 3.1 \\
Total & 735 & 76 & 10.3 & 528 & 71.8 & 46 & 6.3 & 85 & 11.6 \\
\hline
\end{tabular}

were often detected, ${ }^{47,53,54}$ The heterogeneity of $C / D$ recombinants was more than $8 \%$ compared with genotypes A, B, D, E, or $\mathrm{F}$ but was $3.8 \%-8.0 \%$ compared with genotype $C$ based on phylogenetic analysis. ${ }^{53}$ The site of recombination with genotype $D$ was located in the pres2/S region, spanning nt $10-799$ in some isolates and nt 101499 in the other isolates. ${ }^{55,56}$ In other regions of the genome, the sequences of recombinant strains were similar to genotype $\mathrm{C}$.

\section{Occult HBV infection}

Occult HBV infection (OBI) is defined as the persistence of viral genomes in the liver tissue or the serum from HBsAgnegative individuals. ${ }^{57} \mathrm{OBI}$ may persist in the host for years without obvious symptoms of overt HBV infection, ${ }^{58}$ or it may develop into hepatitis, cirrhosis, or HCC. ${ }^{59}$ China is a highly endemic area for HBV infection, and several studies reported prevalence of OBI in different populations. Based on detection of nested polymerase chain reaction (PCR) and real-time PCR, the prevalence of OBI was $0.8 \%(9 / 1146)^{60}$ among healthy young adults in Harbin, all of whom received three doses of the HBV vaccine. With the $\mathrm{HBsAg}(-)$, anti$\mathrm{HBs}(+)$, and anti-HBc(+) vaccines, the rate of OBI was close to $28.8 \%$ in Qidong. ${ }^{61}$ The occult infection may be due to absent or inadequate response to the inoculated HB vaccine ${ }^{61}$ or from infected mothers. ${ }^{60}$ Among mother-teenager pairs, OBI prevalence in mothers was $10.0 \%(6 / 60)$, which was significantly higher than $2.0 \%(2 / 101)$ in teenagers. ${ }^{62}$ The family members of patients with chronic HBV infection were considered high-risk population, with OBI prevalence up to $11 \% .{ }^{63}$ In our previous study, the prevalence of OBI was $4.9 \%(9 / 183)$ in HB-vaccinated infants from HBsAg-positive mothers, ${ }^{56}$ and their anti-HBs levels were lower. In patients with $\mathrm{HBsAg-negative} \mathrm{chronic}$ liver disease and HCC patients, the prevalence of occult HBV infection reached $28.3 \%(45 / 159)$ and $70.4 \%$ (95/135), respectively. ${ }^{64}$

According to reports mentioned above, the strains associated with occult infection were genotype $C, B$, and $C / D$ recombinant. Some strains harbor G145R mutations in " $a$ " determent, where mostly had few escape mutations. The viral loads were almost not more than $10^{4}$ copies $/ \mathrm{ml}$. However, occult HBV may be transmitted not only by blood transfusion or organ transplantation, but also between relatives or from HBV infected mothers. ${ }^{65}$ Therefore, more attention should be paid to occult infection in order to better control the spread of HBV infection.
Immunization prevention of hepatitis B in China

\section{Vaccination against $\mathrm{HBV}$}

The Ministry of Health of China has implemented a series of regulations involving HBV vaccination since 1992. However, unlike other Expanded Program on Immunization (EPI) vaccines, families had to pay for the HBV vaccine before 2001. To encourage cost-effective immunization, the Chinese government decided to integrate HBV vaccination into the EPI, requiring local authorities at all levels to provide free HBV vaccine to all infants from 2002 , with the families only paying the service fee. In 2005, The Chinese government finally adopted a completely free HBV vaccination program for all neonates. ${ }^{66}$ Following a series of interventions, prevalence of HBV infection has significantly declined from $9.8 \%$ in 1992 to $7.2 \%$ in 2006 in China. ${ }^{67}$ In 2009, all youths in China aged below 15 years were vaccinated.

The rate of HBV immunization coverage has increased each year since 1992. A study conducted in Zhejiang Province showed that by 1997, the HBV immunization coverage rate for newborns receiving their first dose reached $96.1 \%$ and for those receiving three doses reached $93.0 \% .{ }^{68}$ Data obtained from a Chinese survey revealed that after completion of the three-dose HBV vaccination regimen, approximately $90 \%-$ $95 \%$ of healthy individuals exhibited protective levels of the anti-HBs antibody. ${ }^{69}$ Vaccination compliance was the lowest among adolescents $(35.9 \%)$ and medicaid recipients $(29.7 \%)$ who received the varicella vaccine and among younger adults who received the hepatitis $\mathrm{A}$ vaccine $(25 \%-$ $35 \%) .{ }^{70}$ Similarly, $35-45 \%$ of subjects failed to complete the $\mathrm{HBV}$ vaccination series.

\section{Passive immunizations with HBIG}

Hepatitis B immune globulin (HBIG) is a human polyclonal $\mathrm{HBV}$ immunoglobulin preparation containing isolated human plasma protein $(50 \mathrm{mg} / \mathrm{ml})$ consisting of at least $95 \%$ human polyclonal IgG antibodies. After administration, HBIG is immediately and completely bioavailable in the recipient's circulation and adequately distributed between plasma and the extravascular fluid. Use of HB vaccine and HBIG in babies born to HBsAg positive mothers after 12 hours of birth tremendously reduces the HBV infection rate.

HBIG was also widely used in the prevention of HBV uterine transmission. In 1995, antepartum treatment that could significantly and safely reduce the failure of postnatal passive or active HBV immunization was reported in China. The treatment involved administration of HBIG 200 IU intramuscularly once a month at the third, second, and first 
month before delivery for chronic HBV infected pregnant women. Since then, similar studies (using HBIG 200 IU per injection or 400 IU per injection $)^{71,72}$ highlighting the efficacy of this regimen were published in China, indicating that this treatment was a standard regimen in China. ${ }^{73}$ However, Yuan's studies in 2006 reported different conclusions. A cohort of $250 \mathrm{HBV}$ e antigen (HBeAg) seropositive pregnant women were randomly assigned to either study (117 cases) or control groups (133 cases), in which the study group received HBIG 400 IU intramuscularly once a month at the third, second, and first month before delivery and the control group received no antepartum treatment. The key findings of this study showed that (i) the regimen failed to significantly reduce the maternal HBV DNA and HBsAg loads; (ii) induced no adoptive immunoprophylaxis for the fetus; and (iii) failed to improve the protective efficacy rate of postnatal passive or active HBV immunization. This study showed that intrauterine transmission of HBV cannot be effectively interrupted even when the pregnant women were administered HBIG prior to delivery.

\section{Challenges of HBV infection control in China}

\section{Higher prevalence of HBV infection in floating population than local residents}

The Chinese Floating Population Development Report in 2013 recently issued by the National Health and Family Planning Commission of the People's Republic of China showed that the floating population was nearly 236 million, $17 \%$ of the total population of China. The mean age of floating population is 28 years, with over half of the working-age born after 1980. However, less than $30 \%$ of the floating population contributed to medical insurance, work-related injury insurance, or maternity insurance in the areas of immigration. A large migrating floating population in urban areas greatly affects the original epidemics and HBV infection patterns. An investigation conducted in Shenzhen demonstrated that the HBsAg prevalence was $21.4 \%$ among 5,824 workers from 136 factories in 2004, of which over $70 \%$ was floating population. ${ }^{74}$ The detection of 5,658 migrant workers in Xianju County of Zhejiang Province from 2005 to 2007 showed that the HBsAg prevalence was $15.9 \% .^{75}$ The serological detection of HBV infection among 1,195 floating populations from Chongqing in 2007 revealed that the $\mathrm{HBsAg}$ prevalence was $8.6 \%{ }^{76}$ These studies demonstrated that the HBsAg prevalence is much higher in floating populations compared with locally registered residents. ${ }^{76}$ Another study conducted in Shenzhen in 2010 demonstrated that the HBsAg prevalence was $7.1 \%(132 / 1873)$, which was higher than locally registered residents $(6.3 \%, 120 / 1898)$, with a positive anti-HBs rate of $67.2 \%$ that was lower than locally registered residents $(76.6 \%) .{ }^{77}$ The high HBsAg prevalence in the floating population is attributed to poor understanding of HBV vaccination, low awareness of HBV infection control and prevention measures, and low educational levels. In addition, most of the floating population is sexually active, another risk factor for HBV infection. Therefore, the floating population in China is a key target for prevention and control of hepatitis $B$, deserving greater attention in the future.

\section{Intrauterine transmission of HBV cannot be completely interrupted}

Intrauterine transmission of HBV is defined as HBV infection caused by the transmission of HBV from pregnant women to fetus through placenta, ${ }^{78}$ which is one route of mother-toinfant transmission. Currently, many hypotheses have been proposed to explain the mechanism of intrauterine transmission of HBV. The first hypothesis relates to HBV transmission from the mother's peripheral blood mononuclear cells (PBMC) to the fetus via placental barrier. ${ }^{79}$ Secondly, HBV infection rate among different layers of placental cells gradually decreases from the maternal side to the fetal side, which supports the hypothesis that intrauterine HBV transmission may be caused through "cellular transfer" in the placenta. ${ }^{78}$ Thirdly, transplacental leakage during threatened preterm labor and abortion leads to fetal HBV infection through the leakage of maternal blood into the blood circulation, thereby inducing intrauterine transmission of HBV. ${ }^{80}$ Currently, it is believed that administration of antiviral drugs at the late stage of pregnancy can effectively prevent the occurrence of mother-to-infant transmission of HBV. ${ }^{81,82} \mathrm{~A}$ metaanalysis of randomized controlled trials (RCTs) regarding the use of antiviral drugs in late pregnancy revealed that lamivudine in HBV carrier-mothers with high viral loads in late pregnancy effectively prevented mother-to-child transmission. ${ }^{83}$ But the HBV intrauterine infection cannot be completely blocked.

\section{Low standardization and poor compliance of antiviral therapy for patients}

Patients with chronic hepatitis B suffer from problems associated with long-time antiviral therapy, high medical cost, possible viral mutations, and relapse, which easily lead to low compliance. Our previous study (unpublished data) showed that among outpatients with hepatitis B, approximately $33 \%$ of the patients with chronic hepatitis B were not aware of currently effective drugs and antiviral therapies for HBV, and $52.8 \%$ never underwent standard antiviral therapy for HBV. Among the patients undergoing treatment, approximately $32.5 \%$ received interferon treatment, and the remainder of patients was mostly treated with nucleoside/ nucleotide drugs. While $87.2 \%$ received medications prescribed, $62.3 \%$ stopped taking medications without reaching the treatment goals. Of these patients, $40 \%$ failed to complete the full course of therapy due to economic difficulties. Therefore, educational intervention for hepatitis B prevention and control should be conducted in China, notably in rural areas. In the future, it will be important to educate patients on how antiviral therapies can prevent and slow poor outcomes in order to increase therapeutic compliance.

\section{High hepatitis B-caused disease burden}

In addition to health consequences, hepatitis B leads to high economic burden for patients, family, and society. It is known that approximately $15 \%-40 \%$ of HBV-infected individuals finally will develop hepatic cirrhosis, hepatic failure, or hepatocellular carcinoma. ${ }^{4}$ It was reported that the annual direct cost of inpatients due to hepatitis B was 41,242.9 RMB Yuan in Guangzhou, including the direct medical cost of 39,097.9 RMB Yuan and direct non-medical cost of 2,145.0 RMB Yuan. The direct cost gradually increased with the 
aggravation of the disease, of which liver transplantation was associated with the highest cost $(119,268.6$ RMB Yuan), followed by severe hepatitis B (73,631.0 RMB Yuan) and acute hepatitis $B\left(12,443.9\right.$ RMB Yuan) ${ }^{84}$ Another study in Ningxia (2010) demonstrated that the annual direct medical and non-medical patient costs due to hepatitis B-related diseases were 26,199.23 and 2,086.53 RMB Yuan, respectively, and the annual direct, indirect and intangible economic burdens were 28,285.76, 3,315.63, and 56,366.41 RMB Yuan, respectively, with a gross economic burden of $87,967.80$ RMB Yuan. In addition, it was found that the direct economic burden of the patients with hepatitis B-related diseases almost approximated the patients' annual family income, which was three-fold greater than the mean family income. ${ }^{85}$ In 2010, a total of 20,000 cases of chronic hepatitis $B$ were reported in Shandong Province, and the annual direct, indirect, intangible, and gross economic burdens were 0.618 , $0.105,1.825$, and 2.548 billion RMB Yuan, respectively, with chronic hepatitis B-related gross cost accounting for approximately $0.06 \%$ of mean per capita gross domestic product (GDP) for the whole province. ${ }^{86}$ Therefore, a search for appropriate interventions to reduce the economic burden is of great practical significance in allocating the limited resources and formulating the health decisions and control strategy for hepatitis $B$.

\section{Conclusions}

With the strengthening of hepatitis B control implementation by the Chinese government, the prevalence of HBV infection is gradually declining in China. Notably, hepatitis B has been classified as one of three communicable diseases that are on high priority with the Chinese government since 2008. In total, 15 national demonstration areas for infectious disease prevention and control program have been initiated, with an investment of over one billion RMB Yuan. In addition to investigating the high risk factors of hepatitis $B$, vaccination has been extended to adults, and standardized antiviral therapy and educational programs have been implemented in rural areas. These measures greatly facilitated the control of hepatitis B in China. A new national seroepidemiological survey is required in the next three to five years to obtain the real prevalence and control of hepatitis $B$ in China to date, in order to develop a revised strategy.

\section{Conflict of interest}

None

\section{Author contributions}

Designing the review (YPY), writing the paper (YPY, HXS, ZHJ, ZJS, and ZSP).

Supportive foundations: This work was supported by China Special Grant for the Prevention and Control of Infection Diseases (2012ZX10004907) and National Nature Science Foundation of China (No. 81072354 and 81370082).

\section{References}

[1] Xia GL, Liu CB, Cao HL, Bi SL, Zhan MY, Su CA, et al. Prevalence of hepatitis B and $C$ virus infections in the general Chinese population. Results from a nationwide cross-sectional seroepidemiologic study of hepatitis $A, B, C, D$, and $E$ virus infections in China, 1992. Int Hepatol Comm 1996;5:62-73.

[2] Liang XF, Bi SL, Yang WZ, Wang LD, Cui G, Cui FQ, et al. Epidemiological serosurvey of hepatitis $B$ in China-declining HBV prevalence due to hepatitis B vaccination. Vaccine 2009;27:6550-6557.

[3] Liaw YF, Chu CM. Hepatitis B virus infection. Lancet 2009;373:582-592.

[4] El-Serag HB. Epidemiology of viral hepatitis and hepatocellular carcinoma. Gastroenterology 2012;142:1264-1273.

[5] Wang LP, Guo Q, Zhang CX, Guo Y, Zhao ZX, Ma JQ, et al. National investigation into and analysis of hepatitis B reporting quality in 2006. Chinese Journal of Disease Control and Prevention 2009;13 69-71.

[6] Health CsMo. China Health Statistics Yearbook of 2005. Peking Union Medical College Press 2005.

[7] Health CsMo. China Health Statistics Yearbook of 2006. Peking Union Medical College Press 2006:230-238.

[8] Health CsMo. China Health Statistics Yearbook of 2007. Peking Union Medical College Press 2007:226-233.

[9] Health CsMo. China Health Statistics Yearbook of 2008. Peking Union Medical College Press 2008:198-205.

[10] Health CsMo. China Health Statistics Yearbook of 2009. Peking Union Medical College Press 2009:237-244.

[11] Health CsMo. China Health Statistics Yearbook of 2010. Peking Union Medical College Press 2010.

[12] Cui FQ, Wang FZ, Zheng W, Chen YS, Gong XH, Wang HQ, Liang XF. Analysis on Reported Cases of Hepatitis B in China in 2005-2007. Chinese Journal of Vaccines and Immunization 2008;14:413-417.

[13] Hou MC, Wu JC, Kuo BI, Sheng WY, Chen TZ, Lee SD, Lo KJ. Heterosexual transmission as the most common route of acute hepatitis $B$ virus infection among adults in Taiwan-the importance of extending vaccination to susceptible adults. J Infect Dis 1993;167:938-941.

[14] Chen Y, Liu LF, Hu J, X., Wang Y, Fan G. The problems existed in the work of heaptitis $B$ virus case report and its recommendations. Occupation and Health 2006;22:2247-2247.

[15] Chen Y, Liu LF, Hu JL, Wang Y, Fan G. Analysis and investigation on case reporting quality of hepatitis $B$. J iangsu Prev Med 2006;17:9-11.

[16] Wang FZ, Cui FQ, Lu Y, Chen YS, Zheng W, Liang XF. Analysis on reported hepatitis $B$ cases on pilot surveillance in 18 counties of 8 provinces of China. Chinese Journal of Vaccines and Immunization 2007;13:309-312.

[17] Wiseman E, Fraser MA, Holden S, Glass A, Kidson BL, Heron LG, Maley MW, Ayres A, Locarnini SA, Levy MT. Perinatal transmission of hepatitis B virus: an Australian experience. Med J Aust 2009;190:489-492.

[18] Xu WM, Cui YT, Wang L, Yang H, Liang ZQ, Li XM, Zhang SL, Qiao FY, Campbell F, Chang CN, Gardner S, Atkins M. Lamivudine in late pregnancy to prevent perinatal transmission of hepatitis $B$ virus infection: a multicentre, randomized, double-blind, placebo-controlled study. J Viral Hepat 2009;16:94103.

[19] Wang JS, Zhu QR. Interruption of the transmission of hepatitis B virus from mother to babies. Chinese journal of hepatology 2002;10:308-310.

[20] Zhu QR, Duan SC. Transmission from mother to baby of the hepatitis B virus. Chinese Journal of Infectious Diseases 1989;7:159-161.

[21] Shao Z], Xu DZ, Xu JQ, Li JH, Yan YP, Men K, Wang XP, Zhang ZY, Jiang QW, Zhang L. Maternal hepatitis B virus (HBV) DNA positivity and sexual intercourse are associated with HBV intrauterine transmission in China: a prospective case-control study. J Gastroenterol Hepatol 2007;22:165-170.

[22] Cui HC, Yan YP, Shao ZJ, Xu DZ, Men K, Xu JQ, Li J. Follow.up study on relationship between hepatitis $B$ e antigens an d intrauterine HBV infection after imm unoprophylaxis. Chinese Journal of Public Health 2006;22:824826.

[23] Yi W, Pan CQ, Hao J, Hu Y, Liu M, Li L, Liang D. Risk of vertical transmission of hepatitis B after amniocentesis in HBs antigen-positive mothers. J Hepatol 2014;60:523-529.

[24] Wang ST, Weng XZ. Five cases of the same serum heaptitis caused by blood transfusion. Journal of Peking University (Health Sciences) 1960;1:014

[25] Lu FM, Li T, Liu S, Zhuang H. Epidemiology and prevention of hepatitis B virus infection in China. J Viral Hepat 2010;17 (Suppl 1)::4-9.

[26] Zhang HW, Yin JH, Li YT, Li CZ, Ren H, Gu CY, Wu HY, Liang XS, Zhang P, Zhao JF, Tan XJ, Lu W, Schaefer S, Cao GW. Risk factors for acute hepatitis B and its progression to chronic hepatitis in Shanghai, China. Gut 2008;57:17131720.

[27] Jia JD, Li LJ. The guideline of prevention and treatment for chronic hepatitis B (2010 version). Chinese Journal of Clinical Hepatology 2011;27:113-128.

[28] Shang G, Seed CR, Wang F, Nie D, Farrugia A. Residual risk of transfusiontransmitted viral infections in Shenzhen, China, 2001 through 2004. Transfusion 2007;47:529-539.

[29] Velati C, Fomiatti L, Baruffi L, Romano L, Zanetti A. Impact of nucleic acid amplification technology (NAT) in Italy in the three years following implementation (2001-2003). Euro Surveill 2005;10:12-14.

[30] Alvarez do Barrio M, Gonzalez Diez R, Hernandez Sanchez JM, Oyonarte Gomez S. Residual risk of transfusion-transmitted viral infections in Spain 
1997-2002, and impact of nucleic acid testing. Euro Surveill 2005;10:2022.

[31] Chiavetta JA, Escobar M, Newman A, He Y, Driezen P, Deeks S, Hone DE, O'Brien SF, Sher G. Incidence and estimated rates of residual risk for HIV hepatitis C, hepatitis B and human T-cell lymphotropic viruses in blood donors in Canada, 1990-2000. CMAJ 2003;169:767-773.

[32] Su Y, Yan R, Duan Z, Norris JL, Wang L, Jiang Y, Xing W, Chen Y, Xiao Y, Li L. Prevalence and risk factors of hepatitis $C$ and $B$ virus infections in hemodialysis patients and their spouses: A multicenter study in Beijing, China. J Med Virol 2013;85:425-432

[33] Alter MJ, Margolis HS. The emergence of hepatitis B as a sexually transmitted disease. Med Clin North Am 1990;74:1529-1541.

[34] Daniels D, Grytdal S, Wasley A. Surveillance for acute viral hepatitis - United States, 2007. MMWR Surveill Summ 2009;58:1-27.

[35] Zou S, Zhang J, Tepper M, Giulivi A, Baptiste B, Predy G, Poliquin D, Morin M, Jones D, Lowewen J, Ogonowski M, Moses S, Elliott L. Enhanced surveillance of acute hepatitis B and C in four health regions in Canada, 1998 to 1999. Can J Infect Dis 2001;12:357-363.

[36] Hahne S, Ramsay M, Balogun K, Edmunds WJ, Mortimer P. Incidence and routes of transmission of hepatitis B virus in England and Wales, 1995-2000: implications for immunisation policy. J Clin Virol 2004;29:211-220.

[37] Wu Q, Li Z, Fan J. A seroepidemiological study on sexually transmitted HBV infection. Zhonghua Liu Xing Bing Xue Za Zhi 1994;15:67-70.

[38] Jia JD. Hepatitis B in China: from guideline to practice. Virol Sin 2008;23: $152-155$.

[39] Ma X, Zhang Q, He X, Sun W, Yue H, Chen S, Raymond HF, Li Y, Xu M, Du H, McFarland W. Trends in prevalence of HIV, syphilis, hepatitis C, hepatitis B, and sexual risk behavior among men who have sex with men. Results of 3 consecutive respondent-driven sampling surveys in Beijing, 2004 through 2006. J Acquir Immune Defic Syndr 2007;45:581-587.

[40] Hu Z, Liu Y, Zhai X, Dai J, Jin G, Wang L, Zhu L, Yang Y, Liu J, Chu M. New loci associated with chronic hepatitis B virus infection in Han Chinese. Nat Genet 2013;45:1499-503.

[41] Chen XL, Sun DX, Zhang XL. Hepatitis B virus genotypes. World ] Gastroenterol 2011(04):389-393.

[42] Sun KX, LI J, Yan L, Sun MS, Ma JF, Chen J, Nie JJ, Zhuang H. Distribution of hepatitis B virus genotypes and subgenotypes in Chinese patients with chronic hepatitis B virus infection. Chinese Journal of Viral Diseases 2011; 03:177-182.

[43] Gao JW, Li YJ, Zhuang H, Li J, Wang J, Dong QM, Chen YJ, Niu JQ, Ma WM, Zhao W, Zhao BA, Zhong JQ. Distribution of hepatitis B virus genotypes in patients with chronic hepatitis B virus infection among 12 cities in China. Zhonghua Liu Xing Bing Xue Za Zhi 2007;28:315-318.

[44] Li X, Liu Y, Xu Z, Wan Z, Bai S, Mao P, Mao Y, Xin S, Xu D. A complete genomic analysis of hepatitis $B$ virus isolated from 516 Chinese patients with different clinical manifestations (pages 1698-1704). J Med Virol 2013;85:16981704.

[45] Zhao HP, Shen YY, Shen R, Li Q, Wang YY, Fu MY. Study on genotypes and subgenotypes of hepatitis B virus among Dai Nationality in Xishuangbanna, Yunnan Province. China Tropical Medicine 2009;9:211-213.

[46] Cao ZL, Gao YT, Liu S, Jing L, Ji Z, Liu T, Liu CJ, Du Z. Detection of HBV genotypes in Lhasa by gene chip. World J Gastroenterol 2007:3500-3506.

[47] Xu YQ, Zhou YD, Bi SL. Preliminary study on genotype of hepatitis B virus detected from Tibetans in China. Zhonghua Shi Yan He Lin Chuang Bing Du Xue Za Zhi 2005;19:118-120.

[48] Xia G, Nainan OV, Jia Z. Characterization and distribution of hepatitis B virus genotypes and subtypes in 4 provinces of China. Zhonghua Liu Xing Bing Xue Za Zhi 2001;22:348-351.

[49] Norder H, Courouce AM, Magnius LO. Complete genomes, phylogenetic relatedness, and structural proteins of six strains of the hepatitis $B$ virus, four of which represent two new genotypes. Virology 1994;198:489-503.

[50] Huang WJ, Zhou C, Wang YC, ZHANG HY, Wu X, Liang ZL, Li HM. Cloning and sequence analysis of complete genome of hepatitis $B$ virus isolates of genotypes B, C, D/C and A from Chinese patients with chronic hepatitis B. World J Gastroenterol 2009:2978-2983.

[51] Lu XB, Wang XL, Deng GH, Kuang XM, Aman GL, Zhang YX, Zhang JL, Wang YM. Distribution and characteristics of hepatitis $B$ virus genotypes in Uighur patients with chronic hepatitis B in Xinjiang province of China. Zhonghua Gan Zang Bing Za Zhi 2007;15:241-244.

[52] Zhuang L, You J, Chen HY, Yu L, Kun L, Tang BZ, Huang JH, Yuan SM, Hutcha $S$, Virasakdi C. Distribution and clinical significance of hepatitis $B$ virus genotypes in patients with chronic HBV infection in Yunnan province, China. World Chinese Journal of Digestology 2007;15:2120-2127.

[53] Zhou B, Wang ZH, Wen SJ, Chen J], Sun J, Hou JL. Identification of two newly discovered subgenotypes of hepatitis $B$ virus genotype $C$. Chinese Journal of Infectious Diseases 2008;26:358-361.

[54] Chen X, Dai B, Liu Z, Gao J, Ji Z, Guo J, Chen G, Deng Z, Shao Z. A novel B/C inter-genotype recombinant of hepatitis $B$ virus identified in north-west China. J Gen Virol 2014;95:153-155.
[55] Wang Z, Liu Z, Zeng G, Wen S, Qi Y, Ma S, Naoumov NV, Hou J. A new intertype recombinant between genotypes $C$ and $D$ of hepatitis $B$ virus identified in China. J Gen Virol 2005;86:985-990.

[56] Su HX, Zhang YH, Xu DZ, Wang B, Zhang L, Li D, Xiao D, Li F, Zhang JX, Yan YP. Occult hepatitis $B$ virus infection in anti-HBs-positive infants born to HBsAg-positive mothers in China. PloS one 2013 8:e70768.

[57] Raimondo G, Caccamo G, Filomia R, Pollicino T. Occult HBV infection. Semin Immunopathol 2013;35:39-52.

[58] Blackberg J, Kidd-Ljunggren K. Occult hepatitis B virus after acute selflimited infection persisting for 30 years without sequence variation. J Hepato 2000;33:992-997.

[59] van Hemert FJ, Zaaijer HL, Berkhout B, Lukashov VV. Occult hepatitis B infection: an evolutionary scenario. Virol J 2008;5:146.

[60] Chen SJ, Zhao YX, Fang Y, Xu WZ, Ma YX, Song ZW, Teng X, Gu HX. Viral deletions among healthy young Chinese adults with occult hepatitis $B$ virus infection. Virus Res 2012;163:197-201.

[61] Xu L, Wei Y, Chen T, Lu J, Zhu CL, Ni Z, Huang F, Du J, Sun Z, Qu C. Occult HBV infection in anti-HBs-positive young adults after neonatal HB vaccination. Vaccine 2010;28:5986-5992.

[62] Dong XL, Yao QQ, Wang XC, Xu HT, Wang XL, Chen SY, Tang ZF, Zheng Y]. Prevalence of occult hepatitis $B$ virus infection and its phylogenetic features among mother-teenager pairs. Zhonghua Liu Xing Bing Xue Za Zhi 2013;34: 210-213.

[63] Kumar GT, Kazim SN, Kumar M, Hissar S, Chauhan R, Basir SF, Sarin SK. Hepatitis B virus genotypes and hepatitis B surface antigen mutations in family contacts of hepatitis B virus infected patients with occult hepatitis B virus infection. J Gastroenterol Hepatol 2009;24:588-598.

[64] Fang Y, Shang QL, Liu JY, Li D, Xu WZ, Teng X, Zhao HW, Fu LJ, Zhang FM, Gu $H X$. Prevalence of occult hepatitis $B$ virus infection among hepatopathy patients and healthy people in China. J Infect 2009;58:383-388.

[65] Walz A, Wirth S, Hucke J, Gerner P. Vertical transmission of hepatitis B virus (HBV) from mothers negative for HBV surface antigen and positive for antibody to HBV core antigen. J Infect Dis 2009;200:1227-1231.

[66] Luo Z, Li L, Ruan B. Impact of the implementation of a vaccination strategy on hepatitis B virus infections in China over a 20 -year period. Int J Infect Dis 2012; 16:e82-88.

[67] Liang XF, Bi SL, Yang WZ, Wang LD, Cui G, Cui FQ, Zhang Y, Liu JH, Gong XH, Chen $Y S$, Wang FZ, Zheng $\mathrm{H}$, Wang $F$, Guo J, Jia ZY, Ma JC, Wang HQ, Luo HM, Li L, Jin SG, Hadler SC, Wang Y. Reprint of: Epidemiological serosurvey of Hepatitis B in China-Declining HBV prevalence due to Hepatitis B vaccination. Vaccine 2013;31:J21-J28.

[68] Yao J, Yang J]. Investigation on Immunization Coverage Rate and Immune Effect of Hepatitis B Vaccine among Newborns in Zhejiang Province. Chinese Journal of Vaccines and Immunization 2000;6:132-134

[69] Liu PB. Certain question discussion of hepatitis B vaccine inoculation. Chinese Journal of Public Health 2000;16:73-74.

[70] Nelson JC, Bittner RC, Bounds L, Zhao S, Baggs J, Donahue JG, Hambidge S], Jacobsen SJ, Klein NP, Naleway AL, Zangwill KM, Jackson LA. Compliance with multiple-dose vaccine schedules among older children, adolescents, and adults: results from a vaccine safety datalink study. Am J Public Health 2009; 99 (Suppl 2)::S389-397.

[71] Li XM, Shi MF, Yang YB, Shi Z], Hou HY, Shen HM, Teng BQ. Effect of hepatitis $B$ immunoglobulin on interruption of $\mathrm{HBV}$ intrauterine infection. World J Gastroenterol 2004;10:3215-3217.

[72] Zou $H$, Chen $Y$, Duan $Z$, Zhang $H$. Protective effect of hepatitis $B$ vaccine combined with two-dose hepatitis B immunoglobulin on infants born to HBsAg-positive mothers. PloS one 2011;6:e26748.

[73] Yuan J, Lin J, Xu A, Li H, Hu B, Chen J, Yao J, Dong H, Jiang M. Antepartum immunoprophylaxis of three doses of hepatitis $B$ immunoglobulin is not effective: a single-centre randomized study. J Viral Hepat 2006;13:597-604.

[74] Xie SS, Li WL. HBV serum markers pattern in 5824 workers. Chinese Journal of clinical medicine research 2005;144:15642-15643.

[75] Zhu QX, Zhang YT, Gu WP, Wang Q. A survey of hepatitis B virus infection in migrant workers in Xianju county from 2005 to 2007. Zhejiang Journal of Preventive Medicine 2009;21:25-25.

[76] Gong T, Gong Y, Deng D, Ye ML. A cross-sectional study on hepatitis B in migrant workers of Chongqing. Modern Preventive Medicine 2007;34:38423844.

[77] Zhang YB, Chen JQ, Hao YT, Chen WH, Ma ZC, Liao YX, Zhang R, Zhu QL. Comparisons and analysis of the hepatitis $B$ infection status of transient population and registered residents in Shenzhen City. Chinese Journal of Disease Control and Prevention 2012;16:424-427.

[78] Xu DZ, Yan YP, Zou S, Choi BC, Wang S, Liu P, Bai G, Wang X, Shi M, Wang X. Role of placental tissues in the intrauterine transmission of hepatitis $B$ virus. Am J Obstet Gynecol 2001;185:981-987.

[79] Bai GQ, Li SH, Yue YF, Shi L. The study on role of peripheral blood mononuclear cell in HBV intrauterine infection. Arch Gynecol Obstet 2011; 283:317-321. 
[80] Xu DZ, Yan YP, Choi BC, Xu JQ, Men K, Zhang JX, Liu ZH, Wang FS. Risk factors and mechanism of transplacental transmission of hepatitis $B$ virus: a case-control study. J Med Virol 2002;67:20-26.

[81] van Nunen AB, de Man RA, Heijtink RA, Niesters HG, Schalm SW. Lamivudine in the last 4 weeks of pregnancy to prevent perinatal transmission in highly viremic chronic hepatitis B patients. J Hepatol 2000;32:1040-1041.

[82] van Zonneveld $M$, van Nunen AB, Niesters HG, de Man RA, Schalm SW, Janssen $\mathrm{HL}$. Lamivudine treatment during pregnancy to prevent perinatal transmission of hepatitis B virus infection. J Viral Hepat 2003;10:294-297.

[83] Shi Z, Yang Y, Ma L, Li X, Schreiber A. Lamivudine in late pregnancy to interrupt in utero transmission of hepatitis $B$ virus: a systematic review and meta-analysis. Obstet Gynecol 2010;116:147-159.
[84] MA QS, Zhou YH, Zhang SX, Liang S, Xiao HW, Xie X, Mei S], Jia WD, Zhang YF, Cui FQ, Wang FZ, Liang XF. Analysis on the direct economic burden and influence factors of HBV-related diseases in Guangzhou. China Preventive Medicine 2011;12:383-386.

[85] Li XQ, Xu HX, Fan XM, Wu Z, Li YF, Zhang SX, Zhuang GH, Zhang LH. Analysis on economic burden and influencing factors of hepatitis B-related diseases patients. Modern Preventive Medicine 2012;39:18711874.

[86] Lu JJ, Li RP, Xu AQ, Zhang L, Song LZ, Yan BY, Ji F, Liu JY, Fang XQ, Wang Z, Zhu DW, Zhang GJ, Feng Y, Xiao ZK, Wang J. Economic burden and related factors on inpatients with HBV-related diseases in Shandong province. Zhonghua Liu Xing Bing Xue Za Zhi 2013;34:267-272. 